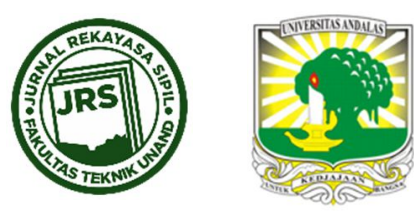

\title{
APLIKASI METODE RAPID VISUAL SCREENING (RVS) DALAM MONITORING KERENTANAN BANGUNAN PEMERINTAHAN DI INDRAGIRI HULU
}

\author{
SRI AGUSTIN ${ }^{1}$, ZULFIKAR DJAUHARI $^{1}$, RENI SURYANITA $^{1^{*}}$ \\ ${ }^{1}$ Teknik Sipil, Universitas Riau, Pekanbaru, Riau \\ *Corresponding author: $ه$ reni.suryanita@eng.unri.ac.id \\ Naskah diterima : 17 Agustus 2019. Disetujui: 13 Maret 2020
}

\begin{abstract}
ABSTRAK
Rapid Visual Screening (RVS) adalah sebuah metode peninjauan kondisi bangunan terhadap gempa secara visual, menggunakan formulir analisis khusus yang merangkum seluruh hasil tinjauan visual dan menghasilkan nilai akhir (final score) minimal 2 (dua) untuk kondisi bangunan yang aman terhadap bahaya gempa. Nilai akhir RVS berdasarkan FEMA 154 dengan ketentuan jika final score kurang dari 2 (dua) maka gedung dinyatakan perlu dievaluasi lebih lanjut. Tujuan penelitian ini adalah untuk menganalisis tingkat risiko bangunan gedung pemerintahan di wilayah Kabupaten Indragiri Hulu terhadap bahaya gempa dan menentukan final score sebagai keluaran dari metode Rapid Visual Screening (RVS). Pengamatan bangunan dilakukan terhadap 4 gedung pemerintahan yaitu Kantor Bupati, Kantor Dinas Pendidikan Kebudayaan, Kantor Dinas Perpustakaan dan Kearsipan dan Bangunan SD Negeri 006 Rengat. Hasil Respons Spektral MCE perioda pendek dengan redaman 5\% (Ss) dan Respons Spektral MCE perioda 1 detik dengan redaman 5\% (S1) pada penelitian ini berada di tingkat Moderate Seismicity. Berdasarkan analisis kondisi bangunan, gedunggedung yang diamati pada penelitian ini tergolong ke dalam kondisi tidak beresiko terhadap gempa bumi. Hal ini dibuktikan dari seluruh final score berada di atas angka 2 (dua). Dengan demikian dapat disimpulkan bangunan gedung pemerintahan pada penelitian ini berada pada kondisi aman dari bahaya risiko gempa.
\end{abstract}

Kata kunci : FEMA 154, final score, Rapid Visual Screening, respons spektral

\section{PENDAHULUAN}

Rapid Visual Screening (RVS) merupakan metode monitoring secara cepat yang dipelopori oleh Federal Emergency Management Agency (FEMA) untuk mendata dan menganalisis kondisi suatu bangunan secara visual yang berpeluang terhadap bahaya gempa bumi (FEMA P-154, 2015). The Federal Emergency Management Agency (FEMA) merupakan lembaga pada Departemen Keamanan Dalam Negeri Amerika Serikat. Lembaga ini bertujuan untuk menanggapi dan bertindak secara cepat terhadap penanggulangan bencana yang terjadi di Amerika Serikat termasuk negara bagiannya. Metode RVS digunakan untuk menganalisis tahap awal pekerjaan dan mengidentifikasi bangunan yang berpotensi berbahaya. Metode

DOI : https://doi.org/10.25077/jrs.16.1.38-48.2020

Attribution-NonCommercial 4.0 International. Some rights reserved 
RVS mengolah data kualitatif yang bersifat subyektif terhadap akar masalah. Pembacaan nilai RVS dicatat dalam formulir khusus yang telah dikembangkan oleh FEMA. Analisis formulir RVS dilakukan melalui pengamatan visual terhadap bangunan gedung, wawancara dan pengumpulan data sekunder (Astuti \& Sangadji, 2016).

Metode RVS yang dikembangkan oleh FEMA ini telah banyak diterapkan oleh berbagai negara seperti yang dilakukan oleh Sinha and Goyal (2004) untuk mengevaluasi gedung di India. Sinha \& Goyal mengevaluasi 10 tipe bangunan yang berbeda berdasarkan material bangunan dan tipe konstruksi bangunan di wilayah perkotaan. Secara umum kajian ini menghasilkan nilai final score lebih kecil dari 0,7 yang mengidentifikasi bangunan yang dievaluasi sangat rentan terhadap bahaya gempa. Dengan demikian hasil RVS merekomendasikan perlunya perbaikan dan evaluasi kondisi bangunan lebih lanjutan. Sedangkan penerapan metode RVS untuk evaluasi bangunan di Indonesia sudah dilakukan oleh beberapa peneliti. Diantaranya kajian yang telah dilakukan oleh Amir (2012) menunjukan evaluasi bangunan secara cepat di Kota Palu dapat dilakukan untuk keadaan bangunan sebelum terjadi gempa bumi dan keadaan bangunan setelah terjadinya gempa bumi. Dengan demikian dapat dibandingkan kondisi bangunan berdasarkan hasil pengamatan cepat melalui metode RVS, apakah kondisi bangunan dalam tingkat resiko rendah atau dengan tingkat resiko tinggi. Kajian yang dilakukan oleh Wahyuni, Aji, and Budi (2017) membandingkan metode RSV dengan SNI 1726 yang dimiliki Indonesia terhadap kerentanan bangunan di Kota Yogyakarta. Hasil kajian menunjukan bangunan yang dievaluasi dengan kedua metode tersebut memberikan tingkat kerentanan yang sama terhadap bahaya gempa.

Evaluasi menggunakan metode RVS dalam skala besar telah dilakukan oleh Gentile, Galasso, Idris, Rusydy, and Meilianda (2019) terhadap 88 bangunan gedung sekolah di Banda Aceh. Usaha yang dilakukan peneliti Gentile dkk merupakan salah satu upaya kampanye penggunaan metode RVS bagi praktisi bangunan di Indonesia. Hal ini dikarena metode RVS lebih praktis dan lebih efektif dalam mengevaluasi kondisi bangunan secara cepat. Penerapan metode RVS telah diterapkan oleh Zulfiar, Jayady, and Jati Saputra (2018) dalam mengkaji kerentanan bangunan cagar budaya di Yogyakarta terhadap bahaya gempa bumi. Hasil penelitiannya menunjukan $63 \%$ bangunan cagar budaya tersebut berpotensi mengalami kerusakan jika terjadi gempa bumi. Hal ini disebabkan oleh bentuk denah dan sistem konstruksi bangunan cagar budaya dibangun tidak sesuai standar pembangunan yang seharusnya begitu juga dengan perbaikan yang telah dilakukan tidak sesuai standar

Penelitian ini merupakan pengembangan kajian sebelumnya yang telah dilakukan oleh tim peneliti terhadap evaluasi bangunan gedung di daerah Riau menggunakan metode RVS (Agustin, Suryanita, \& Djauhari, 2019). Metode lain yang pernah dilakukan sebelumnya dalam mengevaluasi kerentanan bangunan gedung terhadap gempa bumi adalah menggunakan standar ASCE 41-13 (Adeswastoto, Djauhari, \& Suryanita, 2017). Hasil penelitian menunjukan bahwa metode evaluasi kerentanan bangunan di Kota Pekanbaru berdasarkan ASCE 41-13 memiliki ketahanan kinerja bangunan sesuai dengan perencanaan acuan yang telah ditentukan. Untuk melanjutkan kajian yang telah dilakukan, maka dalam penelitian ini evaluasi bangunan dilakukan dengan metode pengalamatan RVS untuk bangunan pemerintahan di daerah Kabupaten Indragiri Hulu Provinsi Riau. Kondisi geografis Indragiri Hulu berada di daerah dataran rendah dengan kontur tanah perbukitan. Kondisi bangunan pemerintahan yang ada rata-rata adalah bangunan berlantai dua hingga berlantai enam. Walaupun secara geografis Kabupaten Indragiri Hulu tidak berada pada daerah rawan gempa, namun kesiapsiagaan terhadap resiko bahaya gempa perlu direncanakan dengan matang. Untuk itu penelitian ini bertujuan menganalisis tingkat risiko bangunan gedung pemerintahan di daerah Indragiri Hulu terhadap bahaya gempa dan 
menentukan nilai akhir (final score) sebagai keluaran dari metode Rapid Visual Screening (RVS).

\section{RAPID VISUAL SCREENING (RVS)}

Metode Rapid Visual Screening (RVS) menilai kerentanan bangunan yang berpotensi bahaya terhadap gempa berdasarkan visual interior dan eksterior bangunan, sehingga pelaksanaannya relatif cepat. Metode RVS merupakan cara evaluasi bangunan secara visual dengan prosedur menggunakan formulir isian yang berisi data primer dan data sekunder bangunan yang ditinjau. Pengisian formulir RVS diikuti dengan skoring sesuai ketentuan yang telah diatur dalam FEMA 154-2002 untuk mendapatkan skor akhir (final score) tiap gedung yang dievaluasi.

Formulir isian data menggunakan metode RVS terbagi 3 kriteria berdasarkan percepatan spectrum respons gempa kecil (low) pada daerah gempa rendah, moderate untuk lokasi dengan gempa sedang dan high untuk lokasi dengan gempa tinggi. Kriteria daerah yang ditampilkan dalam formulir RVS dapat dilihat pada Tabel 1.

Tabel 1. Daerah gempa berdasarkan percepatan respon spectral (Wang \& Goettel, 2007)

\begin{tabular}{lll}
\hline Daerah Gempa & $\begin{array}{l}\text { Respon Akselarasi Spektral, } \\
\text { SA (Periode pendek, atau 0,2 } \\
\text { detik) }\end{array}$ & $\begin{array}{l}\text { Respon Akselarasi Spektral } \\
\text { SA (Periode Panjang, atau 1,0 } \\
\text { detik) }\end{array}$ \\
\hline Rendah (Low) & $\begin{array}{l}\text { Kurang dari 0,167 g (arah } \\
\text { horizontal) }\end{array}$ & $\begin{array}{l}\text { Kurang dari 0,067 g (arah } \\
\text { horizontal) }\end{array}$ \\
\hline Sedang (Moderate) & $\begin{array}{l}\text { Lebih besar dari atau sama } \\
\text { dengan 0,167 g tetapi lebih kecil } \\
\text { dari 0,500 g (arah horizontal) }\end{array}$ & $\begin{array}{l}\text { Lebih besar dari atau sama } \\
\text { kengan 0,067 g tetapi lebih } \\
\text { horizontal) }\end{array}$ \\
\hline Tinggi (High) & Lebih besar atau sama dengan \\
0,500 g (arah horizontal) & $\begin{array}{l}\text { Lebih besar atau sama dengan } \\
\text { 0,200 g (arah horizontal) }\end{array}$ \\
\hline
\end{tabular}

Tahapan pengisian formulir RVS FEMA 154-2002 meliputi: pemilihan seismisitas lokasi, pengisian data umum bangunan, menggambar sketsa bangunan, menentukan occupancy soil, menentukan jenis tanah, identifikasi falling hazard, menentukan jenis bangunan dan jumlah lantai, identifikasi adanya plan Irregularity dan vertical Irregularity, memeriksa standar yang digunakan saat membangun dan terakhir skoring. Proses skoring dilakukan dengan cara melingkari skor yang terdapat di bawah jenis bangunan yang sesuai dengan bangunan yang dievaluasi. Setelah semua dilingkari, maka skor tersebut dijumlahkan. Apabila jumlah skor lebih dari atau sama dengan 2, maka bangunan dinilai tidak rentan, namun apabila skornya kurang dari 2, maka bangunan dinilai rentan dan direkomendasikan untuk dicek kembali menggunakan tata cara FEMA 310.

Ada beberapa langkah yang diperlukan dalam pelaksanaan RVS pada bangunan yang memiliki potensi bahaya gempa. Urutan secara umum pelaksanaan evaluasi menggunakan formulir RVS sebagai berikut:

a. Perencanaan anggaran dan biaya perkiraan.

b. Perencanaan pralapangan, memutuskan prioritas urutan bangunan.

c. Pemilihan data review atau formulir, sesuaj jenis kegempaan pada lokasi pengamatan seperti: Rendah (Low/L), Sedang (Medium/M) dan Tinggi (High/H).

d. Kualifikasi dan pelatihan Screener.

e. Akuisisi dan review data pralapangan. 
f. Review dokumen konstruksi untuk bangunan yang ditinjau.

g. Pelaksanaan RVS.

h. Pemeriksaan kualitas dan penerimaan data lapangan.

\section{METODOLOGI PENELITIAN}

Pada penelitian ini, gedung pemerintahan yang ditinjau terletak di Kabupaten Indragiri Hulu, Provinsi Riau. Gedung-gedung yang dievaluasi tersebut berjumlah 4 gedung yaitu Kantor Bupati Indragiri Hulu, Kantor Dinas Pendidikan dan Kebudayaan, Kantor Kepustakaan dan Kearsipan serta SD Negeri 006 Kota Rengat.

Kerentanan suatu bangunan menggunakan metode RVS dengan acuan FEMA 154 diukur menggunakan formulir seperti pada Gambar 1. Adapun langkah - langkah untuk mengisi formulir Rapid Visual Screening (RVS) sebagai berikut:

1. Verifikasi dan update informasi bangunan yang ditinjau.

2. Survei bangunan untuk mengidentifikasi bentuk dan jumlah lantai, dan mensketsa keseluruhan bangunan serta elevasinya pada formulir.

3. Foto bangunan.

4. Menentukan dan mendokumentasikan jenis hunian.

5. Menentukan jenis tanah dan resiko geologis.

6. Mengidentifikasi penambahan ruangan (renovasi), ketidakteraturan bangunan, dan potensi bahaya dari barang - barang eksterior.

7. Menentukan tipe bangunan untuk mendapatkan nilai minimal bangunan dengan mengidentifikasi material bangunan, konstruksi bangunan, sistem penahan gempa, dan denah bangunan.

8. Mencari penyimpangan bangunan (denah, vertical irragularity, tipe tanah, dan lainlain) yang akan menurunkan nilai bangunan pada formulir pengisian.

9. Menentukan nilai tingkat pertama dengan menambahkan seluruh nilai yang ada termasuk penyimpanganya untuk mendapatkan nilai terakhir (S).

10. Menambahkan informasi tentang kondisi yang tidak sesuai dalam struktur bangunan.

11. Kesimpulan untuk hasil pengamatan bangunan, perlu analisis lanjut atau tidak memerlukan analisis lanjutan.

Parameter data untuk evaluasi pengamatan yaitu data primer dan data skunder. Data primer diperoleh melalui pengamatan lapangan menggunakan formulir RVS sedangkan data sekunder diperoleh melalui pemetaan topografi objek penelitian dan data tanah. Data tanah dan topografi menggunakan data dari profil Kabupaten Indragiri Hulu yang dikeluarkan oleh Direktur Jendral Cipta Karya tahun 2003. Data desain spektra (Ss dan S1) yang terlihat pada Tabel 2 didapatkan dari koordinat suatu bangunan yang ditinjau, kemudian diinput ke Desain Spektra website Pusat Penelitian dan Pengembangan Permukiman (Puskim, 2017).

Bagan alir penelitian dengan metode Rapid Visual Screening (RVS), dapat dilihat pada Gambar 2. Pengamatan yang diperlukan secara keseluruhan adalah bentuk visual dari gedung-gedung yang ditinjau untuk mendapatkan kondisi eksisting yang ada. 


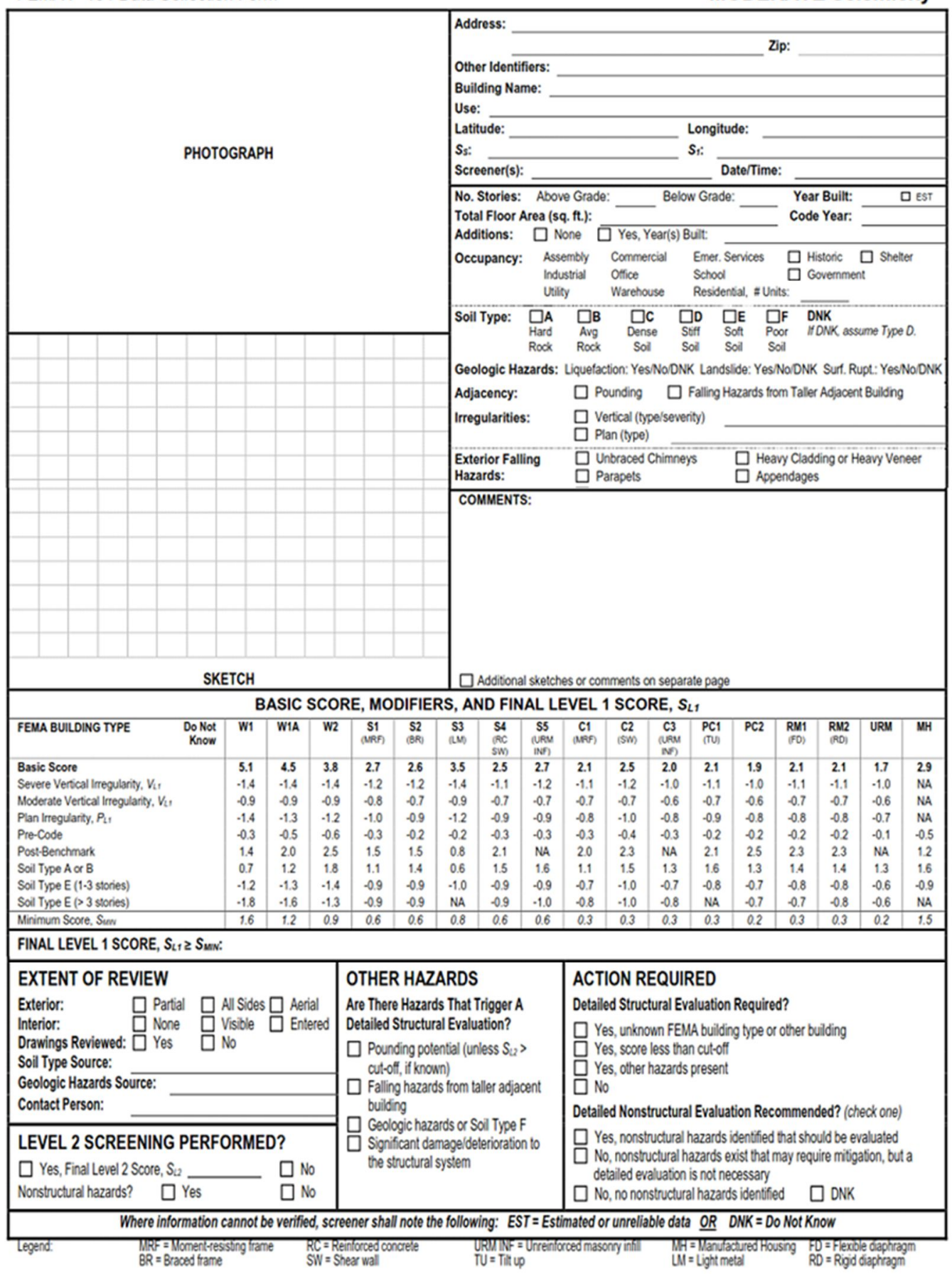

Gambar 1. Formulir pengisian metode Rapid Visual Screening (RVS) (FEMA 154, 2002) 


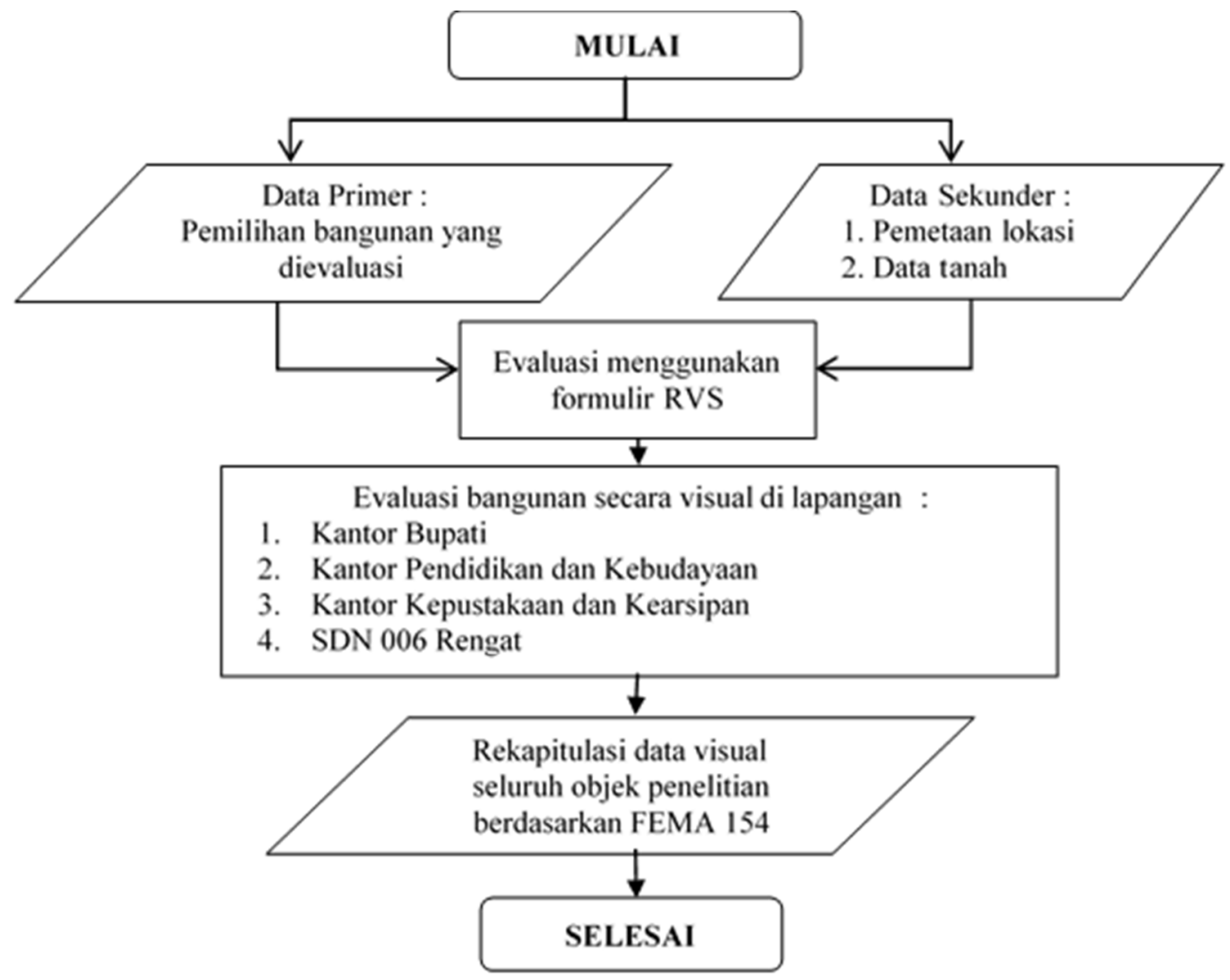

Gambar 2. Bagan Alir Penelitian

Tabel 2. Nilai Ss dan S1

\begin{tabular}{llllll}
\hline No. & Objek & Latitude & Longitude & Ss & S1 \\
\hline 1 & Kantor Bupati & $-0,392224$ & 102,4372 & $0,286 \mathrm{~g}$ & $0,209 \mathrm{~g}$ \\
\hline 2 & $\begin{array}{l}\text { Dinas Pendidikan dan } \\
\text { Kebudayaan }\end{array}$ & $-0,396246$ & 102,4371 & $0,286 \mathrm{~g}$ & $0,209 \mathrm{~g}$ \\
\hline 3 & $\begin{array}{l}\text { Dinas Perpustakaan } \\
\text { dan Kearsipan }\end{array}$ & $-0,376056$ & 102,5567 & $0,208 \mathrm{~g}$ & $0,206 \mathrm{~g}$ \\
\hline 4 & SD Negeri 006 Rengat & $-0,374226$ & 102,5494 & $0,255 \mathrm{~g}$ & $0,195 \mathrm{~g}$ \\
\hline
\end{tabular}

\section{HASIL DAN PEMBAHASAN}

Hasil pembacaan data nilai Respons Spektral MCE perioda pendek, redaman $5 \%\left(S_{s}\right)$ dan Respons Spektral MCE perioda 1 detik dengan redaman 5\% $\left(S_{I}\right)$ berdasarkan koordinat lokasi gedung pada Tabel 2 menunjukkan bangunan gedung yang ditinjau pada penelitian ini, kondisi gedung berada pada tanah dengan Moderate Seismicity. Hasil analisis pada gedung yang ditinjau diklasifikasikan berdasarkan fungsi gedung, jenis tanah dan bahaya non struktural dari gedung tersebut. Adapun peninjauan gedung pada penelitian ini menghasilkan data yang tertera seperti pada Tabel 3 dan Tabel 4. 
Tabel 3. Tabel Klasifikasi Jenis Hunian dan Tipe Tanah sesuai FEMA 154

\begin{tabular}{lllll}
\hline No & Objek Gedung & Jenis Hunian & $\begin{array}{l}\text { Jumlah } \\
\text { Penghuni }\end{array}$ & Tipe Tanah \\
\hline 1 & Kantor Bupati & $\begin{array}{l}\text { Government dan } \\
\text { Office }\end{array}$ & $101-1000$ & E (Soft Soil) \\
\hline 2 & $\begin{array}{l}\text { Dinas Pendidikan dan } \\
\text { Kabudayaan }\end{array}$ & $\begin{array}{l}\text { Government dan } \\
\text { Office }\end{array}$ & $11-100$ & E (Soft Soil) \\
\hline 3 & $\begin{array}{l}\text { Dinas Perpustakaan dan } \\
\text { Kearsipan }\end{array}$ & $\begin{array}{l}\text { Government dan } \\
\text { Office }\end{array}$ & $11-100$ & E (Soft Soil) \\
\hline 4 & SD Negeri 006 & School & $101-1000$ & E (Soft Soil) \\
\hline
\end{tabular}

Keseluruhan data tanah ini tidak dapat dilakukan pengamatan lebih lanjut, dengan berdasarkan formulir tanah (soil). Berdasarkan FEMA 154 tahun 2002, tipe tanah pada gedung yang ditinjau ini harus disesuaikan dengan hasil analisis tanah yang dilakukan ketika bangunan tersebut didirikan.

Tabel 4. Tabel Klasifikasi Bahaya Non - Struktural

\begin{tabular}{llllll}
\hline No & Objek Gedung & Chimneys & Parapets & Cladding & Other \\
\hline 1 & Kantor Bupati & - & $\sqrt{ }$ & - & $\sqrt{ }$ \\
\hline 2 & $\begin{array}{l}\text { Dinas Pendidikan dan } \\
\text { Kabudayaan }\end{array}$ & $\sqrt{ }$ & $\sqrt{ }$ & $\sqrt{ }$ & $\sqrt{ }$ \\
\hline 3 & $\begin{array}{l}\text { Dinas Perpustakaan } \\
\text { dan Kearsipan }\end{array}$ & - & $\sqrt{ }$ & - & $\sqrt{ }$ \\
\hline 4 & SD Negeri 006 & - & - & - & $\sqrt{ }$ \\
\hline
\end{tabular}

Penerapan prosedur RVS pada salah satu gedung yang dievaluasi yaitu gedung Kantor Bupati Indragiri Hulu dapat dilihat pada Gambar 3. Analisis dilakukan berdasarkan pengamatan di lapangan menggunakan formulir yang dikembangkan oleh FEMA.

Berdasarkan hasil analisis untuk klasifikasi dan nilai gedung di Kabupaten Indragiri Hulu, Kantor Bupati termasuk kategori bangunan C2 (Concrete Shear Wall) karena memiliki dinding geser sebagai penopang pergerakan lift untuk perpindahan manusia di dalam gedung dengan nilai dasar (Basic score) sebesar 3,6 untuk Moderate seismicity. Kategori bangunan C1 (Concrete Moment) karena memiliki balok dan kolom yang terbuat dari beton bertulang dengan nilai dasar (Basic score) sebesar 3,0 untuk Moderate seismicity, berfungsi menahan beban lateral dan vertikal yang ada pada gedung. Nilai Modifier untuk Mid Rise (4 to 7 stories) dimiliki oleh gedung ini sebesar $+0,4$ untuk kategori $\mathrm{C} 2$ dan $+0,2$ kategori $\mathrm{C} 1$.

Berdasarkan Gambar 4 denah Kantor Bupati di dapatkan nilai untuk Plan Irregularity sebesar -0,5 untuk tipe bangunan C2 dan C1. Ketidakberaturan berdasarkan denah (Plan Irreguarity) yang dimiliki gedung Kantor Bupati ini dengan kombinasi bentuk antara $U$ Shape dan T-Shape. Gedung dengan eksentrisitas kekakuan yang cukup besar pada sistem pemikul beban lateral ini dapat menimbulkan torsi/puntir di sekitar sumbu vertikalnya. Nilai Modifier Vertical Irregularity tidak terdapat pada gedung ini, karena tidak ada syarat yang terpenuhi dari Modifier Vertical Irregularity, yaitu bangunan dengan kondisi Setback, Hillside dan Soft Story. 


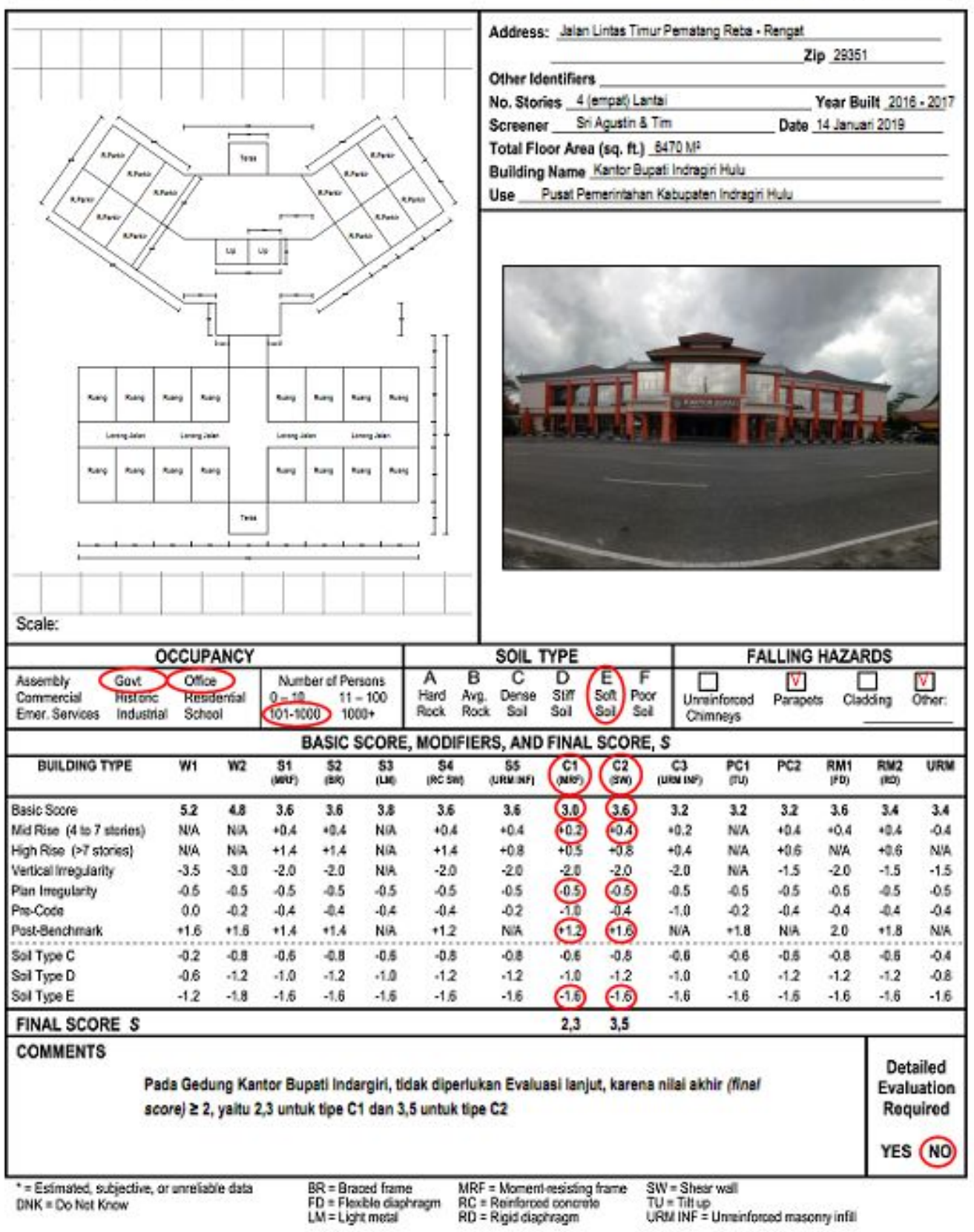

Gambar 3. Formulir Rapid Visual Screening(RVS) untuk evaluasi Gedung Kantor Bupati Indragiri Hulu

Dari hasil pengamatan lapangan gedung Kantor Bupati telah dipugar pada tahun 2016 dan selesai 2017, memiliki nilai Post Benchmark $+1,6$ untuk kategori C2 dan $+1,2$ untuk kategori $\mathrm{C}$. Hal ini didapakan karena gedung didesain dan dibangun setelah dimulainya penerapan dan pelaksanaan peraturan gempa (seismic code) pada tahun 1987 dikeluarkannya peraturan perencanaan bangunan tahan gempa. Nilai Modifier Pre-Codetidak dimiliki pada gedung ini, karena tahun didirikan tidak berada di bawah tahun 1987, sebagai tahun penerapan peraturan gempa. Modifier selanjutnya adalah tipe tanah yang dimiliki Gedung Kantor Bupati yaitu Tipe E Soft Soil mendapatkan nilai modifier sebesar -1,6 untuk tipe gedung $\mathrm{C} 1$ dan C2. Penentuan skor (Final Score) metode Rapid Visual Sreening berdasarkan 
FEMA 154 Tahun 2002 dengan Data Collection Form Moderate Seismicity didapatkan nilai 2,3 untuk kategori Concrete Moment Resisting Frames (C1) dan 3,5 untuk kategori Concrete Shear Wall Buildings (C2).

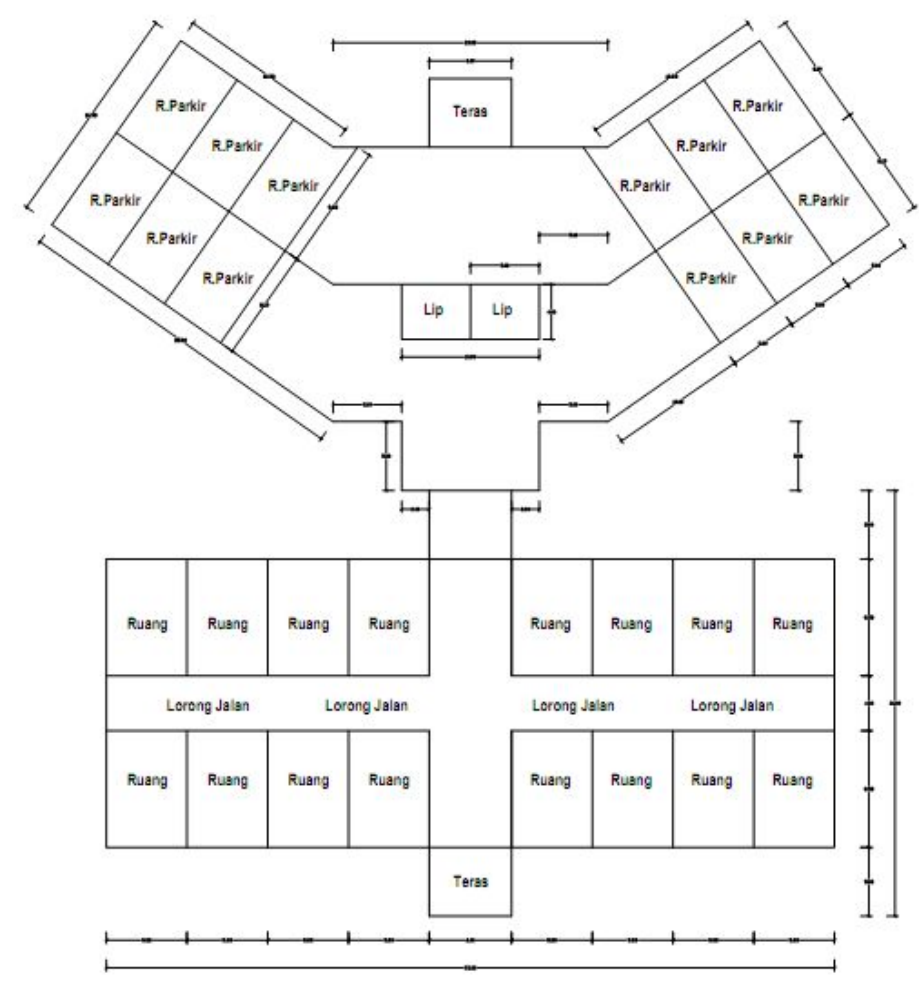

Gambar 4. Denah Kantor Bupati

Dari analisis berdasarkan formulir RVS FEMA 154 tahun 2002, keruntuhan non structural terdapat di semua jenis gedung yang ditinjau. Dengan analisis yang dilakukan, kondisi gedung pada lingkungan pemerintahan kabupaten Indragiri Hulu tergolong tidak beresiko terhadap bahaya gempa, hal ini dibuktikan dari seluruh nilai akhir (final score) berada di atas angka minimal yaitu 2 (dua).

Berdasarkan pembacaan formulir RVS ini gedung-gedung yang ditinjau diberi nilai (Basic Score, Modifier, Final Score) untuk menentukan keandalan gedung yang dievaluasi. Nilai yang didapatkan dari hasil evaluasi RVS berada di atas angka 2 (dua). Sebagai standar dari aturan FEMA 154, jika gedung memiliki nilai di bawah 2 (dua), maka perlu dilakukan analisis lanjut terhadap gedung tersebut, dengan demikian ke 4 gedung pemerintahan yang dievaluasi ini tidak memerlukan analisis lanjut. Berikut data rangkuman analisis gedung yang ditinjau dalam Tabel 5 .

Tabel 5. Tabel Klasifikasi Gedung dan Nilai Skor Gedung

\begin{tabular}{|c|c|c|c|c|c|c|c|c|c|c|c|}
\hline \multirow[b]{2}{*}{$\begin{array}{l}\text { No } \\
\text { - }\end{array}$} & \multirow[b]{2}{*}{ Nama Gedung } & \multicolumn{10}{|c|}{ Parameter penilaian Rapid Visual Screening (RVS) } \\
\hline & & 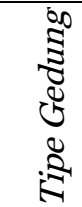 & 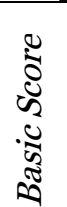 & 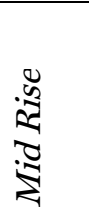 & 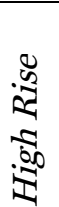 & 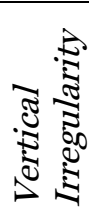 & 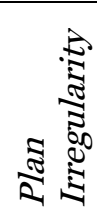 & $\begin{array}{r}8 \\
8 \\
0 \\
1 \\
0 \\
0 \\
2 \\
2\end{array}$ & 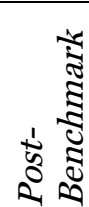 & 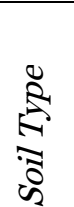 & 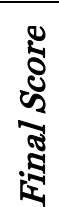 \\
\hline 1 & Kantor Bupati & $\begin{array}{l}\mathrm{C} 1 \\
\mathrm{C} 2\end{array}$ & $\begin{array}{l}3,0 \\
3,6\end{array}$ & $\begin{array}{l}+0,2 \\
+0,4\end{array}$ & - & - & $\begin{array}{l}-0,5 \\
-0,5\end{array}$ & - & $\begin{array}{l}+1,2 \\
+1,6\end{array}$ & $\begin{array}{l}-1,6 \\
-1,6\end{array}$ & $\begin{array}{l}2,3 \\
3,5\end{array}$ \\
\hline
\end{tabular}




\begin{tabular}{|c|c|c|c|c|c|c|c|c|c|c|c|}
\hline \multirow[b]{2}{*}{$\begin{array}{l}\text { No } \\
\cdot\end{array}$} & \multirow[b]{2}{*}{ Nama Gedung } & \multicolumn{10}{|c|}{ Parameter penilaian Rapid Visual Screening (RVS) } \\
\hline & & 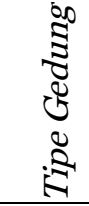 & 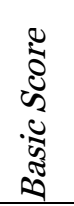 & 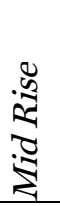 & 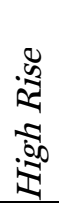 & 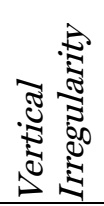 & 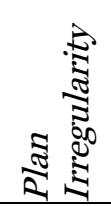 & $\begin{array}{l}8 \\
8 \\
0 \\
1 \\
2 \\
2\end{array}$ & 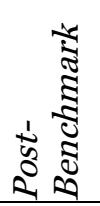 & 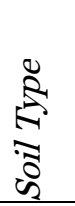 & 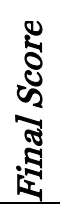 \\
\hline 2 & $\begin{array}{l}\text { Dinas Pendidikan } \\
\text { Kebudayaan }\end{array}$ & $\mathrm{C} 1$ & 3,0 & - & - & - & - & - & $+1,2$ & $-1,6$ & 2,6 \\
\hline 3 & $\begin{array}{l}\text { Dinas } \\
\text { Perpustakaan } \\
\text { Kearsipan }\end{array}$ & $\mathrm{C} 1$ & 3,0 & - & - & - & - & - & $+1,2$ & $-1,6$ & 2,6 \\
\hline 4 & $\begin{array}{l}\text { SD Negeri } 006 \\
\text { Rengat }\end{array}$ & $\mathrm{C} 1$ & 3,0 & - & - & - & $-0,5$ & - & $+1,2$ & $-1,6$ & 2,1 \\
\hline
\end{tabular}

\section{KESIMPULAN}

a. Berdasarkan hasil evaluasi menggunakan metode Rapid Visual Screening (RVS), didapatkan lokasi bangunan yang dianalisis berada di wilayah dengan kondisi gempa sedang (Moderate Seismicity)

b. Keempat bangunan yang dievaluasi memiliki tingkat resiko kerentanan yang rendah dengan dibuktikan nilai final score keseluruhan berada di atas angka dua $(>2)$.

c. Parameter Vertical Irregularity, Plan Irregularity dan Soil Type merupakan parameter yang sangat kuat dalam menentukan evaluasi berdasarkan FEMA 154, karena nilai tersebut sebagai faktor nilai pengurang yang dapat mempengaruhi tingkat resiko kerentanan suatu bangunan terhadap bahaya gempa bumi.

\section{UCAPAN TERIMA KASIH}

Penulis mengucapkan terima kasih kepada DRPM Ristekdikti melalui skema Penelitian Tesis Magister 2019 dan Universitas Riau yang telah mendanai penelitian ini. Semoga hasil penelitian ini dapat memberikan kontribusi bagi riset dan teknologi di Indonesia.

\section{DAFTAR PUSTAKA}

Adeswastoto, H., Djauhari, Z., \& Suryanita, R. (2017). Evaluasi Kerentanan Bangunan Gedung Terhadap Gempa Bumi Berdasarkan ASCE 41-13. SIKLUS: Jurnal Teknik Sipil, 3(2), 86-99. doi:https://doi.org/10.31849/siklus.v3i2.383

Agustin, S., Suryanita, R., \& Djauhari, Z. (2019). Monitoring Kerentanan Bangunan Gedung Dengan Metode Rapid Visual Screening. JURNAL SAINSTEK, ר(1), 15-31.

Amir, F. (2012). Evaluasi Kerentanan Bangunan Gedung Terhadap Gempa Bumi Dengan Rapid Visual Screening (RVS) Berdasarkan FEMA 154. Infrastruktur, 2(1).

Astuti, N. D., \& Sangadji, S. (2016). Evaluasi awal resiko seismik bangunan gedung rusunawa 1,2,3. 19.

FEMA 154. (2002). Rapid Visual Screening of Buildings for Potential Seismic Hazards (March ed.).

FEMA P-154. (2015). Rapid Visual Screening of buildings for potential seismic hazards: a handbook (FEMA P-154)(January ed.): Federal Emergency Management Agency.

Gentile, R., Galasso, C., Idris, Y., Rusydy, I., \& Meilianda, E. (2019). Earthquake And Tsunami Risk Prioritisation of Indonesian Schools Through Rapid Visual Survey. Conference of Earthquake Risk and Engineering Towards a Resillent World, 1-10.

Puskim, D. P. U. (2017). Desain Spektra Indonesia. Retrieved from http://puskim.pu.go.id/Aplikasi/Desain_spektra_indonesia_2011/ 
Sinha, R., \& Goyal, A. (2004). A national policy for seismic vulnerability assessment of buildings and procedure for rapid visual screening of buildings for potential seismic vulnerability. Retrieved from

Wahyuni, E., Aji, P., \& Budi, F. (2017). Study of Rapid Visual Screening of Buildings for High Potential Seismic Hazard According to Indonesian Standard. IPTEK Journal of Proceedings Series, $O(2)$, 19. doi:https://doi.org/10.12962/j23546026.y2017i2.2273

Wang, Y., \& Goettel, K. A. (2007). Enhanced Rapid Visual Screening ( E-RVS ) Method for Prioritization of Seismic Retrofits in Oregon. Nature of the Northwest Information Center, 31.

Zulfiar, M. H., Jayady, A., \& Jati Saputra, N. R. (2018). Kerentanan Bangunan Rumah Cagar Budaya Terhadap Gempa Di Yogyakarta. Jurnal Karkasa, 4(1), 5. doi:https://doi.org/10.32531/jkar.v4i1.67 